\title{
A Corpus-Based Study of Semantic Prosody and Semantic Preference of "Seem"
}

\author{
Weiqian Liu \\ School of Foreign Languages, Beihang University, Beijing, China \\ Email: sjzliuweiqian@163.com
}

How to cite this paper: Liu, W. Q. (2020). A Corpus-Based Study of Semantic Prosody and Semantic Preference of "Seem". Open Journal of Social Sciences, 8, 282-291. https://doi.org/10.4236/jss.2020.85020

Received: May 5, 2020

Accepted: May 22, 2020

Published: May 25, 2020

\begin{abstract}
This paper is a corpus-based analysis of the semantic prosody and preference of "seem" to get a more fine-grained picture of the functions expressed by the marker. The multifunctionality of "seem" (appearance verb, evidential marker, hedging probability, indicating hearsay, etc.) has received a great deal of attention (Aijmer, 2009, Usoniene \& Jolanta, 2013, Langacker, 2017, Marin, 2017, etc.) whilst few studies (if only) have looked on the issue of its profiled meaning thus this empirical research aims to explore the semantic prosody and preference of "seem" as an indicator to determine its primary function. The focus is on examining the semantic prosody, semantic preference and colligations of "seem" which help determines its predominant semantic function. In addition, how different meanings of "seem" interact with its various syntactic patterns and colligations is also investigated. It is argued that there is a close link between certain colligation and the preferred meaning it relates to.
\end{abstract}

\section{Keywords}

Semantic Prosody and Preference, Seem, Primary Function, Colligation

\section{Introduction}

Semantic prosody as one of the most important concepts arisen out of corpus linguistics has been explored extensively both in monolingual and cross-linguistic contexts (Naixing Wei \& Xiaohong Li, 2014). Previous studies have used both semantic prosody and preference as an indicator of the equivalence and translatability between synonyms or translation correspondences. Naixing Wei \& Xiaohong Li (2014), for instance, examines the semantic preference and prosody across English and Chinese for their roles in "achieving equivalence between corresponding lexical items of the two languages". Richard Xiao and Tony Mcenery (2006) analyzed three case studies of near synonyms in English and their close 
translation equivalents in Chinese by comparing their collocational behaviors and semantic prosody. Therefore, it is plausible to use semantic prosody and preference as evidence indicating the primary function of certain polyfunctional markers such as "seem", "appear", etc. which straddles between the boundary of evidentiality (perceptional evidentiality) and epistemic modality (Aijmer, 2009). Seem-type verbs have been in the focus of research for a number of reasons (Mortelmans, 2017) among which its multifunctionality (expressing appearance, evidentiality, hedging probability, indicating hearsay, etc.) plays the key role just as Langacker (2017) notes, "some matrix predicates specify source of information (see, hear, infer, report), others pertain to epistemic certainty (think, suspect, know, likely, certain), while others are reasonably viewed either way (seem, apparent, conjecture)". The multifunctionality makes it a quite challenging task to precisely characterize the primary function expressed by "seem".

Given such gap, this corpus-based study will address the following issues:

1) Exploring the semantic prosody and preference of "seem" as an indicator of its primary function.

2) Identifying the correspondent relation between distinct patterns and colligations of "seem" and its preferred functions.

\section{Analytical Concepts}

\section{Semantic Prosody, Semantic Preference and Colligation}

By semantic prosody, various definitions have been given, e.g. "consistent aura of meaning with which a form is imbued by its collocates" (Louw, 1993: p. 157), "the spreading of connotational colouring beyond single word boundaries" (Partington, 1998: p. 68), among many others where the sharing point is that semantic prosody refers not only to the meaning of a single word but the collocational meaning arising from the interplay between a given node and its typical collocates from large language corpora rather than intuition. The semantic prosody essentially indicates the communicative purpose of the speaker, and is on the pragmatic side of the semantics-pragmatics continuum (Sinclair, 1996: p. 87).

Sinclair (1991: pp. 6-7, 2004: pp. 142-147) also uses the term to refer to "the consistent discourse function of the unit formed by a series of co-occurrences: the 'unit of meaning', typically occurred in an extended sequence where semantic prosody is one of the identifying features." In the present study, therefore, attitudinal meaning and prosodic meaning are interchangeable when discussing the semantic prosody of a unit of meaning (Naixing Wei \& Xiaohong Li, 2014).

Sinclair's model of extended unit of meaning comprises four parameters:

1) Collocation (the relationship between a node and individual words);

2) Colligation (the relationship between a node and grammatical categories);

3) Semantic preference (semantic sets of collocates);

4) Semantic prosody (affective meaning) (Richard Xiao \& Tony Mcenery, 2006).

Distinct from semantic prosody, semantic preference, also known as attitudinal preference, is defined as "the frequent co-occurrence of a lexical item with 
items expressing a particular evaluative meaning" (Hunston, 2007: p. 266). In other words, semantic preference refers to some "sharing semantic features of a lexical set of frequently occurring collocates" (Stubbs, 2002: p. 449).

In short, semantic prosody refers to the attitudinal meaning of the "extended unit" as a whole at a more abstract level whilst semantic preference describes the sharing semantic features of a set of typical collocates of a given node word.

\section{Research Methodology}

Semantic prosody generally could be analyzed in corpus-driven, corpus-based or integrated approach (Wei Naixing, 2002). The present study adapts the corpus-based approach exploring the main semantic prosody and preference based on colligations. FLOB corpus with more than 1 million running words is used to extract the data.

\section{Results and Discussion}

This section examines in detail the colligation, semantic preference and semantic prosody of the node word for characterizing the primary function and patterning feature of "seem". The key word occurred 195 times in FLOB and 100 concordances were randomly extracted for scrutiny with the span from " -5 " to " +5 " focusing on semantic prosody, preference and colligation patterning features of the node word. For the limited space, the following 50 concordances are presented for an illustration and checking for the collogiation, semantic preference and semantic prosody o the node word "seem".

1) McEnroe, Pat Cashand Boris Becker seem to have lost their love of

2) Muslim in the sub-continent may seem undesirable and irrational to outsiders

3) she is. It would seem from your article that you don't

4) stone slates, and some farmers seem to have taken the view:

5) the interval, but the evening will seem better by so doing.

6) in the sticks does not seem to have mattered too much. If a

7) history of religion. It would seem that Muslims would have to admit

8) has done so, and does not seem to have suffered the divisive, destruction

9) want convenience, but they do seem to lose some of their taste

10) to a cold shower was soon to seem the height of luxury; although an

11) The redesign may seem simple, almost conservative, ...

12) our shortcomings? We still seem to hold this curious image of

13) the population our water supplies seem back to normal: the panic is

14) never changes'; now it would seem that, at last, we have an

15) historians, perhaps not surprisingly, seem uncomfortable with any ...

16) are quite clear. In others they may seem frustratingly unclear. This is because,

17) present-day taste, it may seem fairly indigestible, but Dickens and his

18) 111 periods of his life his letters seem more dutifully filial than ... 
19) This may seem a slightly sour picture but I am

20) in religion, loyalty did not seem to be as important as it was,

21) lots bought in. This did not seem to be good news, but the dealers

22) created in performance. This would seem to be an integral part of

23) railroad travel and ventilation seem to make a population moral and

24) days after our return makes the journey seem already strangely distant, as if

25) in the past week, it will seem clear that he has failed on the

26 ) the surface. And yet there would seem to have been a real change of

27) Labour or Liberal Democrat, seem devoted. We can achieve much greater ...

28) Formation (Eocene, USA) where fossils always seem to be compressed.

29) predicting AIDS cases. It might at first seem that the larger the fraction of

30) responsible and demanding jobs do seem to find a reduction in the ...

31) Regan and Stephen Clark. It might seem curious that the whole complex is

32) elementary school. The commissioners seem to have devoted their main effort

33) of endogenous reasons (such as voluntary quits) seem to fit in better with the

34) "come from?" the answer became: "They always seem to find it for wars, so"

35) function stability criteria seem to provide powerful tools for delineating

36) was to our liking. It made noise seem further away, it made sleeping cosier.

37) You seem to ascribe to Martyn qualities of

38) called for another. "The house must seem a bit empty."

39) outsider other things in his life seem as important as the all-consuming ...

40) her. She didn't seem to be breathing. He felt her wrists

41) it's just their bodies, they seem to want to do good, and close

42) Edward shook his head. "You seem more of a regular here than"

43) crack the ice: "Well, you seem to be quite a bright girl, don"”

44) "Swerving loyalty doesn't seem to have been an unqualified success"

45) strange about you, Tansy. You only seem to come alive when you're ...

46) "Neville, on the other hand, can't seem to get the hang of them."

47) "to life-and now, even the locals seem to love us!"

48) "with wealth was that it didn't seem to make any difference to anyone"

49) "You don't seem to eat much either," said

50) Africa and through Iberia; others seem to be pioneering new ranges

\subsection{Colligation of "Seem"}

Collocates of "seem" in each position are scrutinized starting from the $\mathrm{N}+1$ where frequent co-occurring collocates with their occurring frequency are as follows: “to" (28/50), “adjectives” (8/50), "that” (3/50), “article” (3/50), “prepositions" (2/50), "others" (6/50) (occurring times/total number). Observing the 
concordances more closely we found that a colligation of infinitive construction "seem + infinitive" is firstly confirmed as its most frequently used pattern, which conforms to the previous study that the infinitive constructions of seem is the most frequent and grammaticalized syntactic pattern seem appears in and function as semi-auxiliaries expressing weak epistemic modality (Aijmer, 2009).

Out of those eight adjectives and two prepositions occurring in the $\mathrm{N}+1$ position, there are two adjectives and one preposition followed by a complementizer "that" introducing a complement clause (1 - 3). In the similar vein, articles appearing in the $\mathrm{N}+1$ positions all co-occurring in the immediate context either with a noun phrase $(4-5)$ or an adjective phrase (6) next to them as illustrated in the following concordances:

1) She is. It would seem from your article that you don't

2) in the past week, it will seem clear that he has failed on the

3) Regan and Stephen Clark. It might seem curious that the whole complex issue

4) to a cold shower was soon to seem the height of luxury; although an

5) This may seem a slightly sour picture but I am

6) called for another. "The house must seem a bit empty.

$7)$ are quite clear. In others they may seem frustratingly unclear.

8) present-day taste, it may seem fairly indigestible, but Dickens...

9) periods of his life his letters seem more dutifully filial than ...

10) days after our return makes the journey seem already strangely distant, as if

Moreover, four adjectives appear in other positions at the right side of "seem" forming adjective phrases (AP) in addition to those bare adjectives immediate to seem at " $\mathrm{N}+1$ " as illustrated in 7 to 10 above.

Therefore, colligationally, in light of the concordances, "seem" tends to co-occur with "to", introducing infinitival, "that"1, introducing complement clause and a "noun or adjective" phrase on its right sides where it serves as a catenative verb, copular verb and matrix verb respectively. All the three colligational patterns are illustrated below with the its frequency on the right side:

- seem to + VP (seem as a catenative verb)

- seem $+\mathrm{AP} / \mathrm{NP}$ (seem as a copular verb)

- seem + that + clause (seem as a matrix verb)

The observation above echoes with the previous research on the major construction types of "seem" where "it takes part in a large number of collocations." (Kjellmer, 1994). Syntactically, "seem" has three main uses: copular verb (e.g. seem obscene); verb with clausal complement (seems that), and catenative verb (seem to) (Johansson, 2007).

Scrutinizing left collocates of the node word reveals that a colligation of modality both explicit (may, would, must, can't, etc.) and implicit (always seem to, etc.)

1"that" construction includes those that are not immediate to seem as "seem clear that...". 
frequently co-occur with "seem" up to 17 times out of the 50 concordances indicating an inference and probabilistic attitudinal meaning expressed by the speaker. In detail, out of the 17 modal expressions, 8 modals colligate with copular "seem", 7 colligate with "seem + that + clause" pattern and 4 of those co-occur with "seem to", all describing the speaker's commitment on the proposition. The node word serves as main verb in all identified concordances thus nouns are attracted to colligate with seem on the left side serving as subjects, where in the colligational pattern "seem + that + clause", all subjects are impersonal "it".

Therefore, three major colligations of seem are extracted as follows:

1) N. + seem to + VP

2) N. + modals + seem + AP/NP

3) it + modals + that + clause.

Among these three colligations, "seem to" is the most frequently used one accounting for $56 \%$, consistent with the previous studies on the syntactic constructions of "seem" that "Seem to is the most grammaticalized form and can be regarded as an evidential marker which is similar to the modal auxiliaries" (Aijmer, 2009). Quirk et al. (1985) also regards both "seem to" and "appear to" as catenatives because of their auxiliary like properties. Therefore, it is reasonable that "seem to" in our data rarely co-occur with modal auxiliaries because "seem to" itself, like a modal verb, can express speakers' weak uncertainty towards the evens and state of affairs.

\subsection{Semantic Prosody and Preference of "Seem"}

In the left side of "seem", collocates are mainly nouns and modal auxiliaries in which most of the nominal collocates are neutral in semantic preference such as:

"Muslim; farmers, evening, a cold shower, redesign; population; letters, water supply, ventilation; fossils, Democrat, journey, noise; house; swerving loyalty". The right side collocates in the vicinity of the node word subsumes three subsets:

1) Desirability and positiveness of certain events: (14\%)

better, back to normal, moral

2) Mixed and neutrality: (14\%)

have taken the view, curious image, as important as, an integral part

3) Undesirability and unpleasantness of certain events: (72\%)

have lost, undesirable, you don't, sour, indigestible, uncomfortable, would have admit, have suffered, lose, luxury, simple, conservative, good news but...(concession), clear that...failed..., not the necessity, a bit empty, ....

It is clear shown that "seem" tends to attract right side collocates with negative and unpleasant semantic features regarding the event or state of affairs, which accounts for $72 \%$ with illustrations as follows:

1) Muslim in the sub-continent may seem undesirable and irrational to outsiders

2) called for another. "The house must seem a bit empty."

3) historians, perhaps not surprisingly, seem uncomfortable with any harsher... 
4) are quite clear. In others they may seem frustratingly unclear. This is because,

5) present-day taste, it may seem fairly indigestible, but Dickens and his

Though nouns on the left are mostly neutral, the negation construction, for example, "didn't seem to make any difference", "not have matter too much", "don't seem to, didn't seem to", "can't seem to", etc. attributes the whole construction with an undesirable semantic preference as illustrated:

1) in religion, loyalty did not seem to be as important as it was,

2) lots bought in. This did not seem to be good news, but the dealers

3) "Neville, on the other hand, can't seem to get the hang of them."

Table 1 profiles the semantic preference and semantic prosody of "seem" identified above.

In addition to the primary undesirable semantic preference, modal auxiliaries and expressions, for instance, would, may, must, will, can, can't etc. appear in all three colligations of the node indicating speaker's uncertainty towards the proposition. Therefore, we may conclude that collocates of "seem" subsumes three categories of semantic subsets: desirability, neutrality and undesirability in which unfavorable and unpleasant attitude towards the event and state of affairs dominates as the semantic preference. And a semantic prosody of inference prevails among all three patterns of "seem" implying speaker's uncertainty and hedging probability, which indicates that the primary function of "seem" is inferential and hedging probability reducing speaker's commitment towards certain event.

The statistical result demonstrates that "seem" prefers a semantic context of "inference”, expressing a “speaker's commitment or certainty regarding the information represented in the embedded proposition." (López-Couso \& Méndez-Naya, 2014: p. 38). The semantic concept of "inference" is a subdomain of "evidentiality and epistemic modality" where the two categories overlap (Faller, 2002: p. 10). This echoes with the findings that "seem" combines epistemicity with evidentiality (Faller, 2002; Langacker, 2017, etc.).

Table 1. Semantic prosdy and preference of "seem".

\begin{tabular}{lll}
\hline $\begin{array}{l}\text { Node word: seem } \\
\text { Collocates }\end{array}$ & $\begin{array}{c}\text { Freq (\%) Semantic } \\
\text { Prosody }\end{array}$ & $\begin{array}{c}\text { Semantic } \\
\text { Preference }\end{array}$ \\
\hline $\begin{array}{l}\text { better, back to normal, moral, a larger fraction, fit in } \\
\text { better with, devote, }\end{array}$ & desirability & \\
$\begin{array}{l}\text { have taken the view, curious image, as important as, an } \\
\text { integral part, curious that, further away, to be breathing }\end{array}$ & neutrality & $\begin{array}{c}\text { inference on } \\
\text { the probability } \\
\text { of events }\end{array}$ \\
$\begin{array}{l}\text { have lost, undesirable, sour, indigestible, uncomfortable, } \\
\text { would have admit, have suffered, lose, luxury, simple, } \\
\text { conservative, good news...failed...; at first seem... not } \\
\text { the necessity a bit empty, .... }\end{array}$ & undesirability & \\
\hline
\end{tabular}


For the reason why "seem" prefers a semantic prosody of "undesirability", it conforms to our human intuition and practical experience that it is our instinct to hope a low possibility of undesirable events happening, in other words, the less likely the better. Therefore, we tend to "infer" the happening of those unpleasant events making "undesirability" pertaining to "inference and uncertainty".

\subsection{Correspondence Relationship between Colligational Patterns and Semantic Preference}

Table 2 profiles the frequency of each subset of semantic preference in each colligation type extracted in 4.1 aiming at finding whether a certain link exists between a certain colligation and its preferred semantic meaning.

It is clear that when a "seem to" pattern occurs, speaker is much more possible to express his or her uncertainty about something undesirable and unpleasant and the second colligation (modal + seem $+\mathrm{NP} / \mathrm{AP}$ ) strongly relates to both "desirability" and "undesirability". When there is a "seem" clause, it is very possible the unpleasant attitudes are expressed.

\section{Conclusion}

In this article, colligations, semantic preference and semantic prosody of the verb "seem" have been examined from FLOB as an indicator to determine the primary function of the multifunctional marker. First of all, three major types of colligations are identified: 1) "N + seem to+ V."; 2) "N + modals +seem +AP/NP"; 3) "It + modals + seem + that+ clause" with the first infinitive pattern occurs most frequently (56\%), consistent with the semi-auxiliary property of "seem to" expressing weak uncertainty of the speaker. Given that observation, the whole unit of meaning comprises a semantic prosody of speaker's weak inference and uncertainty, according to which the primary function of "seem" relates to inferential evidentiality and epistemic modality. Moreover, within the semantic prosody, collocates of the node subsumes three semantic preferences: undesirability, neutrality and desirability with undesirability the predominant one taking up $74 \%$, which accords with human instinct that all human beings instinctively hope all unpleasant events happen the less likely the better thus unpleasant attitudes towards event tends to be attracted in a local context with semantic prosody of uncertainty and weak speaker commitment. Finally, there seems to be a link between certain colligations and a preferred semantic preference where undesirability prevails in all three colligations and only when "seem" is used as a copular verb, desirability is likely to be expressed.

Table 2. Relation between the colligation of seem and its semantic preference.

\begin{tabular}{lccc}
\hline \multicolumn{1}{c}{ Node word: seem } & \multicolumn{3}{c}{ Semantic Preference } \\
\hline \multicolumn{1}{c}{ Colligation } & Desirability & Neutrality & undesirability \\
\hline 1) seem to & $20 \%$ & $30 \%$ & $50 \%$ \\
2) modals + seem + NP/AP & $43 \%$ & $5 \%$ & $52 \%$ \\
3) modals + seem + that + clause & $0 \%$ & $33 \%$ & $67 \%$ \\
\hline
\end{tabular}




\section{Conflicts of Interest}

The author declares no conflicts of interest regarding the publication of this paper.

\section{References}

Aijmer, K. (2009). Seem and Evidentiality. Functions of Language, 16, 63-88. https://doi.org/10.1075/fol.16.1.05aij

Faller, M. (2002). Semantics and Pragmatics of Evidentials in Cuzco Quechua. Un Published Dissertation.

Hunston, S. (2007). Semantic Prosody Revisited. International Journal of Corpus Linguistics, 12, 249-268. https://doi.org/10.1075/ijcl.12.2.09hun

Johansson, S. (2007). The English Verb Seem and Its Correspondences in Norwegian: What Seems to be the Problem? In K. Aijmer (Ed.), A wealth of English: Studies in Honour of Göran Kjellmer (Gothenburg Studies in English 81) (pp. 221-245). Göteborg: Acta Universitatis Gothoburgensis.

Kjellmer, G. (1994). A Dictionary of English Collocations, Based on the Brown Corpus (3 Vols). Oxford: Clarendon Press.

Langacker, R. W. (2017). Evidentiality in Cognitive Grammar. In J. I. M. Arrese, G. Haßler, \& M. Carretero (Eds.), Evidentiality Revisited (pp. 13-55). Amsterdam: John Benjamins. https://doi.org/10.1075/pbns.271.02lan

López-Couso, M. J., \& Méndez-Naya, B. (2014). From Clause to Pragmatic Marker. A Study of the Development of Like-Parentheticals in American English. Journal of Historical Pragmatics, 15, 36-61. https://doi.org/10.1075/jhp.15.1.03lop

Louw, B. (1993). Irony in the Text or Insincerity in the Writer?-The Diagnostic Potential of Semantic Prosodies. In M. Baker, G. Francis, \& E. Tognini-Bonelli (Eds.), Text and Technology: In Honour of John Sinclair (pp. 157-176). Amsterdam: Benjamins. https://doi.org/10.1075/z.64.11lou

Marin, A. J. I. (2017). Multifunctionality of Evidential Expressions in Discourse Domains and Genres: Evidence from Cross-Linguistic Case Studies. In Evidentiality Revisited (pp. 196-223). https://doi.org/10.1075/pbns.271.09mar

Mortelmans, T. (2017). Seem-Type Verbs in Dutch and German: Cognitive Grammar, Functional and Discourse-Pragmatic Perspectives. https://doi.org/10.1075/pbns.271.06mor

Quirk, R., Sidney, G., Geoffrey, L., \& Jan, S. (1985). A Comprehensive Grammar of the English Language. London: Longman.

Sinclair, J. M. (1991). Corpus, Concordance, Collocation. Oxford: Oxford University Press.

Sinclair, J. M. (1996). The Search for Units of Meaning. TEXTUS: English Studies in Italy, 9(1).

Sinclair, J. M. (2004). Trust the Text: Language, Corpus and Discourse. London: Routledge.

Stubbs, M. (2002). Two Quantitative Methods of Studying Phraseology in English. International Journal of Corpus Linguistics, 7, 215-244. https://doi.org/10.1075/ijcl.7.2.04stu

Usonienè, A., \& Jolanta, Š. (2013). A Cross-Linguistic Look at the Multifunctionality of the English Verb Seem. In J. I. M. Arrese, M. Carretero, J. ArúsHita, \& J. van der Auwera (Eds.), English Modality: Core, Periphery and Evidentiality (pp. 281-336). Berlin: De Gruyter Mouton.

Wei, N. X. (2002). General Methods for Semantic Prosody. Foreign Language Teaching and Research, 34, 302-307. 
Wei, N. X., \& Li, X. H. (2014). Exploring Semantic Preference and Semantic Prosody across English and Chinese: Their Roles for Cross-Linguistic Equivalence. Corpus Linguistics and Ling Theory, 10, 103-138.

https://doi.org/10.1515/cllt-2013-0018

Xiao, R., \& McEnery, T. (2006). Collocation, Semantic Prosody, and Near Synonymy: A Cross-Linguistic Perspective. Applied Linguistics, 27, 103-129.

https://doi.org/10.1093/applin/ami045 